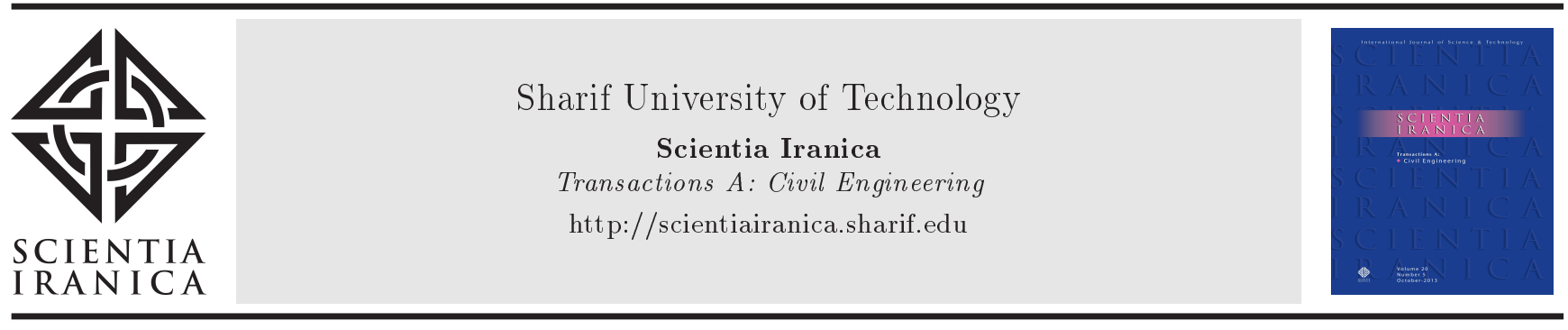

\title{
A combination of computational fluid dynamics, artificial neural network, and support vectors machines models to predict flow variables in curved channel
}

\author{
A. Gholami, H. Bonakdari*, A.A. Akhtari, and I. Ebtehaj \\ Department of Civil Engineering, Razi University, Kermanshah, Iran.
}

Received 6 June 2017; received in revised form 11 July 2017; accepted 11 September 2017

KEYWORDS
ANN;
SVM;
CFD;
Velocity;
Flow depth;
$60^{\circ}$ bend.

\section{Introduction}

Artificial channels and rivers, with different sizes, geometries, and hydraulic characteristics, are rarely direct routes and have many curves in the path. Flow in curves is under the influence of longitudinal pressure gradient and the centrifugal force, which make the flow pattern in curved path different from that in direct path. The interaction of these two forces creates a

\footnotetext{
*. Corresponding author. Tel.: +98831427 4537;

Fax: +988314283264

E-mail addresses: Gholamiazadeh1@gmail.com (A.

Gholami); bonakdari@yahoo.com (H.Bonakdari);

akhtari@razi.ac.ir (A.A. Akhtari); isa.ebtehaj@gmail.com

(I. Ebtehaj)
}

doi: $10.24200 /$ sci.2018.20695 secondary flow. These flows cause changes in the velocity distribution and water surface depth profiles [1]. Therefore, understanding the flow pattern in the bend is necessary to study the river behaviour. In recent years, many researchers have focused on numerical and observational studies of the flow behaviour of the curved paths. Shukry [2] was the first researcher who carried out several experimental studies on the flow pattern in bends. Then, Rozovskii [3] studied the velocity distribution and shear stress in sharp and mild bends, and recommended keeping the maximum velocity position constant from inside to the end of the bend. DeVriend and Geoldof [4] investigated the distribution of water surface profiles in bends and evaluated the superelevation in the cross section and non-linearity of bends. Bergs [5] performed wide experimental studies on the flow pattern in a U-shaped flume. He pointed to 
spiral flows and stated that the rotating flows within 3-5 $\mathrm{m}$ of entry were strengthened and, during the exit from the bend, disappeared. Ye and McCorquodale [6] carried out extensive studies on mild and sharp bends. They referred to the presence of super-elevation and secondary currents from the beginning of the bend up to the internal cross section. Blanckaert and Graf [7] conducted experimental studies on turbulent flow in a movable bed with a $120^{\circ}$ sharp bend. Barbhuiya and Talukdar [8] conducted an experimental study on scour pattern in a $90^{\circ}$ bend. The results showed that the maximum measured velocity was larger than the mean velocity. Ramamurthy et al. [9] and Gholami et al. [10] performed extensive experimental studies on the $90^{\circ}$ sharp bend and evaluated the velocity and flow depth profiles in bend. The locations of maximum velocity and nonlinearity of water surface transverse profiles were important. In addition to experimental studies, there are numerical studies on the flow pattern in the curved channels. They are carried out by Computational Fluid Dynamics (CFD) or new common soft computing methods. In the field of CFD, Leschziner and Rodi [11] performed extensive studies on the sharp and mild bends. It was observed that the main factor of maximum velocity component transferring forward to the outer wall at the end of sharp bend was the longitudinal pressure gradient, whereas in mild bends (like the numerical model used in [12]), the main displacement cause was the secondary flow. The results indicated that, unlike in the mild bends that maximum velocity in most parts of the channel was in the outer bend, in sharp bends, it was in the internal bend. DeMarchis and Napoli [13] numerically investigated the velocities and flow depth profiles distribution in a threedimensional flow in a $270^{\circ}$ bend within channel and declared that at the final cross section of the bend, the velocity value in the outer channel wall would be the largest. Bodnar and Prihoda [14], using the finite volume method, investigated the water surface pattern in a $90^{\circ}$ bend and focused on the non-linearity slope of water surface. Gholami et al. [15] extensively studied the pattern of flow depth changes in $120^{\circ}$ sharp bend using a numerical model. They referred to nonlinearity of transverse water surface profiles in different cross sections. They presented two relationships of the maximum and minimum flow depths with the normal depth in curved channel. Bonakdari et al. [16], using the CFD model, studied the bend effect on the velocity pattern in a circular section channel. Zeng et al. [17] evaluated flow in a curved open channel with a $193^{\circ}$ sharp bend using eddy simulation and showed satisfactory results for velocity distribution in the main and secondary flows in cross sections. Through channel depth analysis, it was shown that there was erosion around the outer bend. Gholami et al. [18] simulated the complete flow pattern in $60^{\circ}$ sharp bend using
Finite Volume Method (FVM) based on the available experimental model. They referred to high accuracy and low error of the numerical model in predicting flow variables in $60^{\circ}$ bend.

In recent decades, the use of soft computing methods to reduce cost and computational time in hydrology and hydraulics science has been increased [19-35]. The application of these methods to the study of the flow pattern in bends can be summarized as follows: the ability of ANN model and Genetic Algorithm (GA) in the evaluation of velocity profiles in $90^{\circ}$ mild bend was investigated by Bonakdari et al. [36]; their results showed high accuracy of the ANN model in estimating the flow variable values. Sahu et al. [37] pointed out the ability of the ANN model in the study of velocity profiles in the meanders. ANN and CFD results were compared with the analytical solution by Gholami et al. [38]; also, Fenjan et al. [39] evaluated the ability of CFD and ANN models in comparison with experimental results in the study of flow pattern in a $90^{\circ}$ sharp bend. Moreover, they emphasized the accuracy of ANN model in flow pattern prediction, especially for the distribution of water surface profiles. ANN model, due to the reduced time and computational costs in comparison with the CFD model, is preferred. Gholami et al. [40] showed the ability of Gene Expression Programming (GEP) model in the prediction of flow patterns in a $90^{\circ}$ sharp bend at 5 different discharges in flow velocity field evaluation. Gholami et al. [41] evaluated the flow pattern in sharp bends using classification methods associated with ANN models. They referred to the increase in accuracy of the classification method in comparison with formal Multi-Layer Perceptron (MLP) and Radial Basis Functions (RBF) models.

The main goal of this paper is assessing the CFD method performance in comparison with Artificial Intelligence (AI) techniques in $60^{\circ}$ sharp bend that, to the best of the authors' knowledge, has not been considered in previous studies. Therefore, three numerical models including CFD model (based on FLUENT software) and two AI techniques (ANN and SVM) are utilized and evaluated in the prediction of velocity and flow depth in $60^{\circ}$ sharp bend. Experimental results for 6 different discharge flows of $5,7.8,13.6,19.1,25.3$, and $30.8(1 / \mathrm{s})$ achieved by Akhtari et al. [42] are used for training and testing AI models. All the three models are verified in comparison with the observed results in velocity and flow depth prediction. Various statistical indices are used to evaluate and compare the models and the superior model will be introduced.

\section{Material and methods}

\subsection{Experimental model}

Akhtari et al. [42] conducted a thorough experimental 


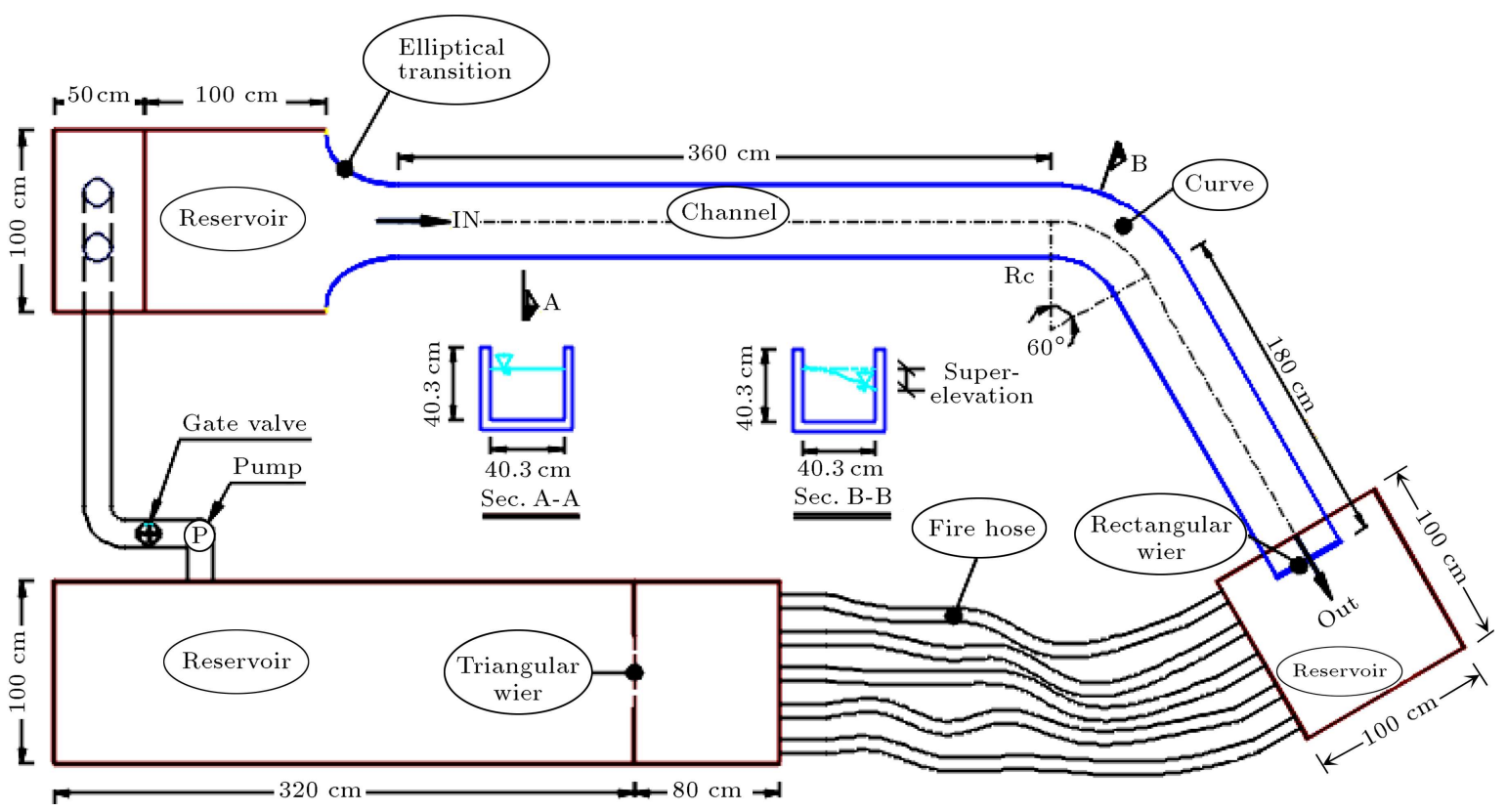

Figure 1. Geometrical shape of the flume used in this paper.

Table 1. Different experimental hydraulic properties.

\begin{tabular}{cccccc}
\hline $\begin{array}{c}\text { No. of } \\
\text { test }\end{array}$ & $\begin{array}{c}\text { Normal depth } \\
\boldsymbol{y}(\mathbf{c m})\end{array}$ & $\begin{array}{c}\text { Discharge } \\
\boldsymbol{Q}(\mathbf{l} / \mathbf{s})\end{array}$ & $\begin{array}{c}\text { Velocity } \\
(\mathbf{m} / \mathbf{s})\end{array}$ & $\begin{array}{c}\text { Froude } \\
\text { number }\end{array}$ & $\begin{array}{c}\text { Reynolds } \\
\text { number }\end{array}$ \\
\hline 1 & 4.5 & 5 & 0.273 & 0.42 & 12460 \\
2 & 6 & 7.8 & 0.321 & 0.42 & 18460 \\
3 & 9 & 13.6 & 0.374 & 0.40 & 28940 \\
4 & 12 & 19.1 & 0.394 & 0.36 & 36860 \\
5 & 15 & 25.3 & 0.419 & 0.34 & 44705 \\
6 & 17.6 & 30.8 & 0.435 & 0.33 & 50830 \\
\hline
\end{tabular}

research on $60^{\circ}$ sharp bend channels in the hydraulics laboratory of Ferdowsi University in Mashhad. The channel under examination had three parts: the 360 $\mathrm{cm}$ long straight inlet channel, the $60^{\circ}$ curved channel with $60.45 \mathrm{~cm}$ central radius of the bend $\left(R_{c}\right)$, and the $180 \mathrm{~cm}$ long straight outlet channel. The cross sections of the intended flume were square shaped with a width $(b)$ of 40.3 and a height $(h)$ of $40.3 \mathrm{~cm}$, and the bed and the walls were made of Plexiglas. The geometrical shape of the flume is shown in Figure 1. Six different hydraulic conditions are considered in the experiments in this paper, as shown in Table 1. A one-dimensional propeller velocity-meter and a micrometer (mechanical bathometer) are used to read the axial velocities and water surface depth, respectively, in the flume. The precision of the micro-meter is $0.1 \mathrm{~mm}$ and the precision of the propeller is $2 \mathrm{~cm} / \mathrm{s}$. The velocity-meter is located by Vernier ruler and analog caliper in the transverse direction with precision of $0.5 \mathrm{~mm}$ and depth direction with precision of 0.1 $\mathrm{mm}$, respectively [43]. Finally, the propeller measures the velocity in flow direction (axial velocity or radius velocity). Also, in internal bend cross sections (e.g., $10^{\circ}, 20^{\circ}, 30^{\circ}, 40^{\circ}, 50^{\circ}$, and $60^{\circ}$ cross sections), the flow velocity is read in channel axis direction by velocitymeter. In internal cross sections, the longitudinal and transversal velocities $\left(V_{x}\right.$ and $V_{y}$ ) are found using the velocity obtained by velocity-meter, which is broken in $X$ and $Y$ directions.

\subsection{Numerical models}

\subsubsection{Computational Fluid Dynamics (CFD) model}

Different control volumes are considered for the whole flow fields in FLUENT software. Then, the NavierStokes governing equation (in fluid flow) is integrated in each control volume. The integrated algebraic equation in each control volume is calculated and separated via different plans. The simulation of the flow in every $60^{\circ}$ bend under study is three-dimensional, the Volume of Fluid (VOF) multiphase model is used, and the "flow in open channel" option is activated [44]. In order to complete the preparation process of the numerical 
model, the "PRESTO" plan is used for expanding the pressure, the "PISO" plan for velocity-pressure coupling, the "Quick" plan for momentum and volume fraction, and the "Second Order Upwind" for separating the displacement sentences. Also, relaxation coefficients below one are used for pressure, momentum, turbulence kinetic energy $(k)$, and turbulence kinetic energy dissipation rate $(\varepsilon)$ to prevent the divergence of the solution. The essential time step for solving the equations is considered to be equal to 0.001 with regards to the divergence process of this simulation.

Gambit software is used to create the geometry and meshing of the solution field. To adjust the meshing in bend, the grid near the floor, walls, interior of the bend, and the interface surface between two phases, finer and coarser grids in the rest of the network is considered. Overall, the considered grid sizing has 225000 nodes $(50 \times 50 \times 90$ nodes in width, depth, and length, respectively) for a $60^{\circ}$ bend. Figure 2 shows a view of the gridding $60^{\circ}$ bend model. Also, the dimensions of the used mesh in CFD are presented in Figure 2 in detail.

In the present paper, the "Velocity Inlet" boundary condition is used separately for water and air in the inlet as the air velocity is considered to have a very small value $(0.0001 \mathrm{~m} / \mathrm{s})$, and flow velocity is applied in accordance with each laboratorial setup (Table 1). Furthermore, the "Pressure Outlet" is considered for the outlet and free surface of channel as boundary condition. Also, in the channel inlet the "Pressure Inlet" is considered as boundary condition for two phase flow of fluid and air (with atmospheric pressure

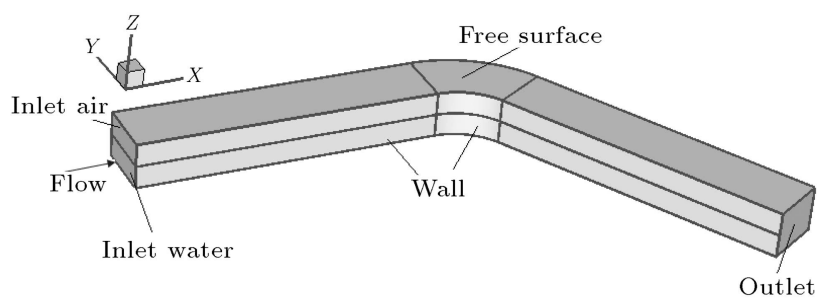

Figure 3. Computational scope and boundary conditions for $60^{\circ}$ bend.

value). The floor and walls of the channel undergo the "Wall" boundary condition using standard wall function. A scheme of the computational scope and the boundary conditions governing the $60^{\circ}$ bend is presented in Figure 3.

\subsubsection{Overview of artificial neural network model}

Artificial neural networks were inspired by the performance system of human brain. The most important component of these networks is named neuron. The ANN models are arranged in three different input, hidden, and output layers. Generally, there are only one input layer, one output layer, and one or more hidden layers. In the present paper, the artificial intelligence tool in MATLAB software is used to design a Multi-Layer Perceptron Neural Network (MLP NN) model in prediction of flow variables in curved channel. Figure 4 shows a general view of this network. The specific weights are used to connect the neurons to each other in designing the network. The input layer introduces the input variables to the model with neurons and transfers them to the hidden layer. The neurons

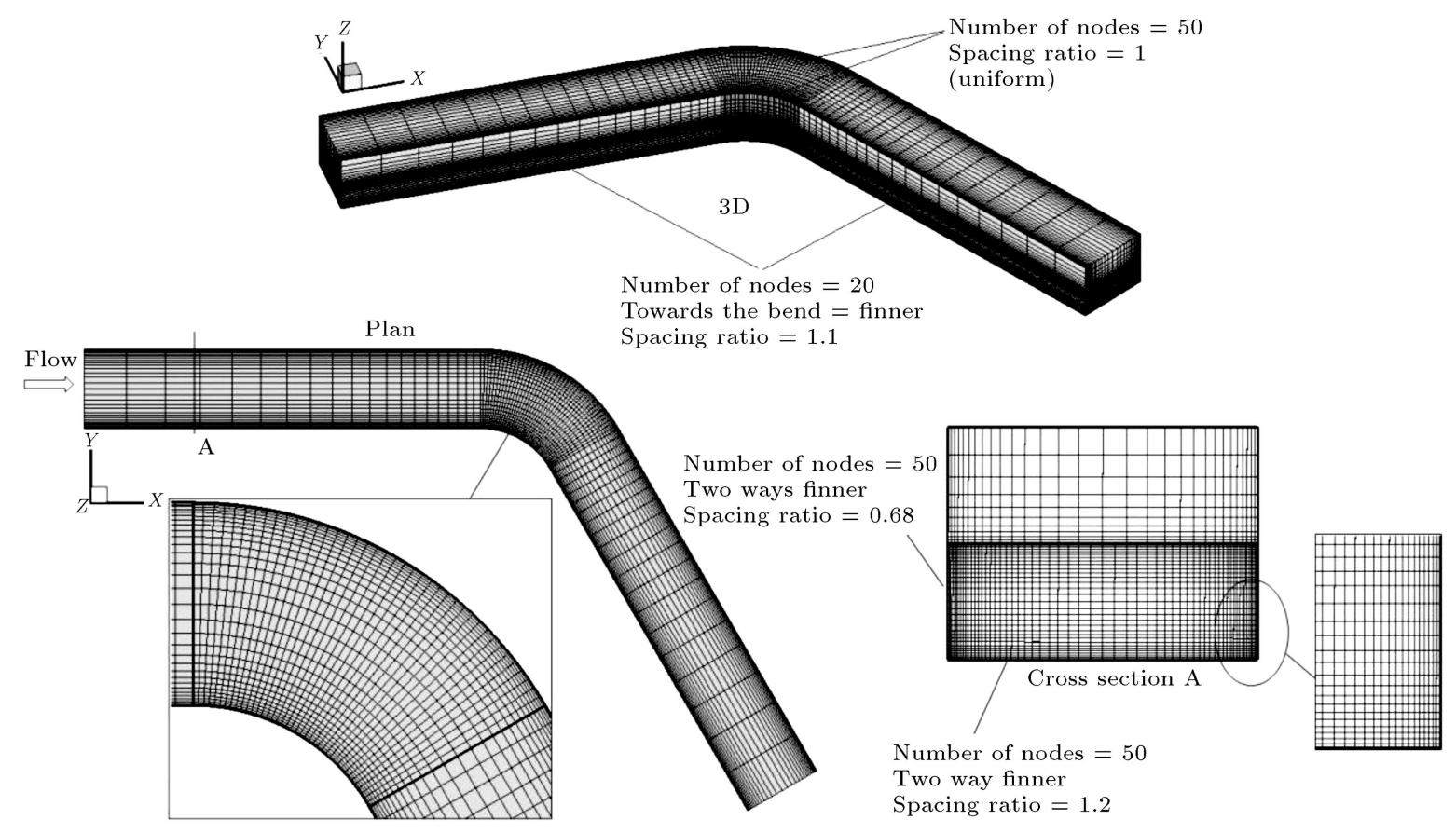

Figure 2. Flow field gridding in plan and cross section of $60^{\circ}$ bend. 


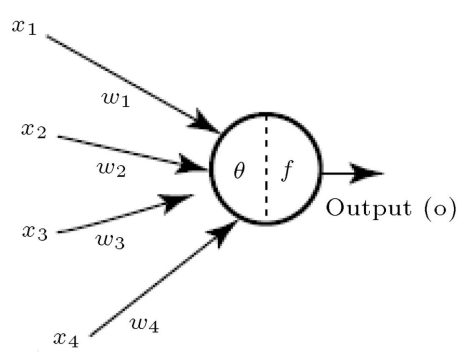

(a)

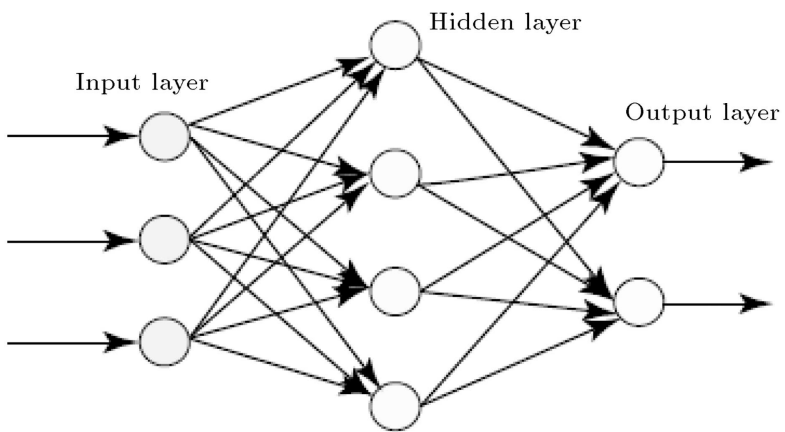

(b)

Figure 4. Architecture of (a) an artificial neuron and (b) a multi-layer artificial neural network.

of input layer are collected by hidden neurons using weighted summation. Also, the activation function is used to make nonlinear mapping between input and output layers. In the present paper, the MLP model uses sigmoid activation function [29,45, and 46]. The numbers of input and output model variables are considered as the neuron numbers of input and output layers, respectively. Determination of weight coefficient in MLP model is named training. In this study, the "back propagation" algorithm is used for training process through Levenberg-Marquardt (LM) method [47]. The "stop" training for the criteria is considered to consist in 100 epochs, which is achieved when the model converges completely $[19,48]$. The error level between ANN model and the observed data is considered to determine the number of the epochs (iterations). Model convergence should be achieved for each number of iterations. In this study, the number of iterations is considered 100 for MLP model.

Moreover, for water surface depth prediction, the numbers of neurons in input and output layers are considered 3 and 1, respectively. Also, two hidden layers are selected associated with 10 neurons in each layer. In the velocity prediction model, the neurons numbers in input, one hidden, and output layers are considered 3,40 , and 1 , respectively.

\subsubsection{Overview of Support Vector Machines (SVM) model}

Support Vector Machines (SVM) modeling was firstly introduced by Vapnik [49] based on statistical learning theory. The SVM is utilized in classification and regression problems known as SVC and SVR (in current study), respectively. The SVM maps the sample space to a high-dimensional feature space to discover an optimal segregating hyper plane [50]. It avoids the curse of dimensionality and over-fitting that occur in traditional machine learning techniques such as Artificial Neural Network (ANN). The calculation of error through SVR modelling is based on structural risk minimization principle, which is different from empirical risk minimization principle employed in conventional neural networks [49]. Therefore, SVR models reduce the generalization error rather than the training error.

The main objective in modelling by SVR is the estimation of functional dependency, $f(\vec{x})$, a set of data points, $X=\left(\vec{x}_{1}, \vec{x}_{2}, \ldots, \vec{x}_{l}\right) \in R^{n}$, and target variable $Y=\left(\vec{y}_{1}, \vec{y}_{2}, \ldots, \vec{y}_{l}\right)\left(y_{i} \in R\right)$. By assuming that all samples are produced from an unknown function of probability distribution $P(\vec{x}, y)$ :

$$
F=\left\{f \mid f(\vec{x})=(\vec{w}, \vec{x})+B: \vec{w} \in R^{n}, R^{n} \rightarrow R\right\},
$$

where $B$ and $\vec{w}$ are coefficients which are different for each problem. The function $f(\vec{x})$, which minimizes the risk function, should be determined. It is defined as:

$$
R[f(\vec{x})]=\int l(y-f(\vec{x}), \vec{x}) d P(\vec{x}, y),
$$

where $l$ is the loss function utilized to calculate the deviation between estimated $f(\vec{x})$ and target values. Considering the unknown probability distribution function of $P(\vec{x}, y), R[f(\vec{x})]$ cannot be minimized directly. Thus, the empirical risk function is calculated as:

$$
R_{e m p}[f(\vec{x})]=\frac{1}{N} \sum_{i=1}^{N} l\left(y_{i}-f\left(\vec{x}_{i}\right)\right) .
$$

This approach is not recommended without any regularization. Thus, a regularized risk function with the smallest sharpness among the whole functions, which minimizes the empirical risk function, is utilized as follows:

$$
R_{r e g}[f(\vec{x})]=R_{e m p}[f(\vec{x})]+\gamma\|\vec{w}\|^{2},
$$

where $\gamma$ is a positive constant. The additional term in the above-mentioned equation decreases the model space and then, controls the complexity of the problem solution. Therefore, this expression can be considered in the following form:

$$
R_{r e g}[f(\vec{x})]=C \sum_{x_{i} \in X} l_{\varepsilon}\left(y_{i}-f\left(\vec{x}_{i}\right)\right)+\frac{1}{2}\|\vec{w}\|^{2},
$$

where $C$ is a positive constant parameter, which is 
known as penalty factor (additional capacity control), and should be determined beforehand. The parameter $C$ shows the influence of the trade-off between weight vector $\|w\|$ and an approximation error. Increase in this parameter penalizes larger errors, leading to reduction of estimation error, which is attained through increasing the regression vector. The loss function, which is known as $\varepsilon$-intensive loss function, is considered as follows:

$$
l_{\varepsilon}\left(y_{i}-f\left(\vec{x}_{i}\right)\right)= \begin{cases}0 & \text { for }\left|y_{i}-f\left(\vec{x}_{i}\right)\right|<\varepsilon \\ \left|y_{i}-f\left(\vec{x}_{i}\right)\right| & \text { otherwise }\end{cases}
$$

This function has the benefit that it does not require all the input data for explanting the regression vector $\vec{w}$. When the function is synthesized with the regularization term $\left(0.5 \times\|\vec{w}\|^{2}\right)$, it behaves as a biased estimator. Determination of $\varepsilon$ is simpler than $C$ and it is mostly given as the favourable percentage of the output values $\left(y_{i}\right)$. Therefore, the nonlinear function is given through a function that minimizes Eq. (5), subject to Eq. (6), in the following form [49]:

$$
f(x)=\sum_{i=1}^{N}\left(a_{i}^{*}-a_{i}\right) K\left(x, x_{i}\right)+B
$$

where $a_{i}^{*}$ and $a_{i}$ are the Lagrange multipliers, $K\left(x, x_{i}\right)$ is the kernel function, and $B$ is the bias. Assuming that the average of data is zero, which can be attained by pre-processing, the bias is dropped.

The kernel function provides operations which act in the input space rather than in the potential feature space. Thus, a kernel function in the input space is comparable with an inner product in the feature space. Generally, the kernel functions handled by the SVM are linear Radial Basis Functions (RBF) in sigmoid and polynomial models. RBF is the most commonly used kernel function, which leads to accurate prediction as well as simplicity and credibility with the hydraulic problems [51-54]. This kernel function is employed in this study, which is computed as follows:

$$
K\left(x, x_{i}\right)=\exp \left(-\gamma\left\|x-x_{i}\right\|^{2}\right)
$$

where $\gamma$ is the kernel parameter and equal to $1 /\left(2 \sigma^{2}\right)$. Choosing $\gamma, \varepsilon$, and $C$ parameters affects the prediction accuracy, which is made by RBF kernel function. The optimum values of constant parameters in the developed SVM for flow depth and velocity field are $(C=8 ; \varepsilon=0.005 ; \gamma=0.01)$ and $(C=3 ; \varepsilon=0.05$; $\gamma=0.01)$, respectively, which are obtained by trial and error.

\subsubsection{Datasets}

The input variables for predicting water surface and velocity are 3 numbers that are coordinates of points in the $X$ and $Y$ directions, and flow discharge $(Q)$ and the output variables are the corresponding velocity and water surface depths of these points.

The axial velocity or radial velocity is measured by experiments in all cross sections. Before the bend cross section (40 $\mathrm{cm}$ before the bend), in similar experimental measurements, the velocity predicted by CFD is axial velocity (velocity in flow direction), $V_{x}$, of which the corresponding experimental data is considered for SVM modelling. After the bend cross sections (40 $\mathrm{cm}$ and $80 \mathrm{~cm}$ after the bend) and internal cross sections (e.g., $10^{\circ}, 20^{\circ}, 30^{\circ}, 40^{\circ}, 50^{\circ}$, and $60^{\circ}$ ), the velocities in $X$ and $Y$ directions $\left(V_{x}\right.$ and $\left.V_{y}\right)$ are predicted by CFD model; then, the catching up of these two velocities ( $V_{x}$ and $V_{y}$ ) is calculated and $V_{T}$ (total velocity or obtained axial velocity) is considered for drawing velocity profile distributions. In these sections, the axial velocity measured by the experimental model in each transversal point is considered for ANN and SVM modelling.

In velocity and water depth prediction models, 130 experimental data are selected for each discharge in 13 transverse points located on 10 different cross sections, namely $40 \mathrm{~cm}$ before the bend; on $0^{\circ}, 10^{\circ}$, $20^{\circ}, 30^{\circ}, 40^{\circ}, 50^{\circ}$, and $60^{\circ}$; and 40 and $80 \mathrm{~cm}$ after the bend. Thus, in 6 discharges $((Q): 5,7.8,13.6,19.1$, 25.3 , and $30.8(1 / \mathrm{s}))$, there are a total of $780(130 \times 6)$ data for each velocity and flow depth prediction.

In the present paper, out of 780 data, 546 data (70\% of the whole data) and 234 data (30\% of the whole data) are chosen for training and testing models, respectively, in each velocity and flow depth prediction. Other methodologies such Genetic Algorithm (GA) and a Self-Organizing Map (SOM) for dividing data are suggested, which reduce the error indices in the conventional data division techniques [55]. The used velocity values are depth averaged velocity in each point. Figure 5 shows the coordinates of transverse points and different cross sections used for measurement of velocity and water surface in $60^{\circ}$ bend.

\subsection{Statistical measurement of model performance}

In order to evaluate the difference between the obtained and actual values, there are many methods to calculate the error: absolute error indices such as Root Mean Square Error (RMSE), Mean Absolute Error ( $M A E)$, Mean Absolute Relative Error (MARE), and Mean Absolute Percentage Error $(M A P E)$. These indices represent the differences between observational and modeled parameters in the same units and scales. The closer the values of these indices to zero, the higher the accuracy of the models will be. Correlation coefficient $(R)$ is an index of descriptive statistics, which describes the degree to which two variables are correlated and the direction of the correlation. The 


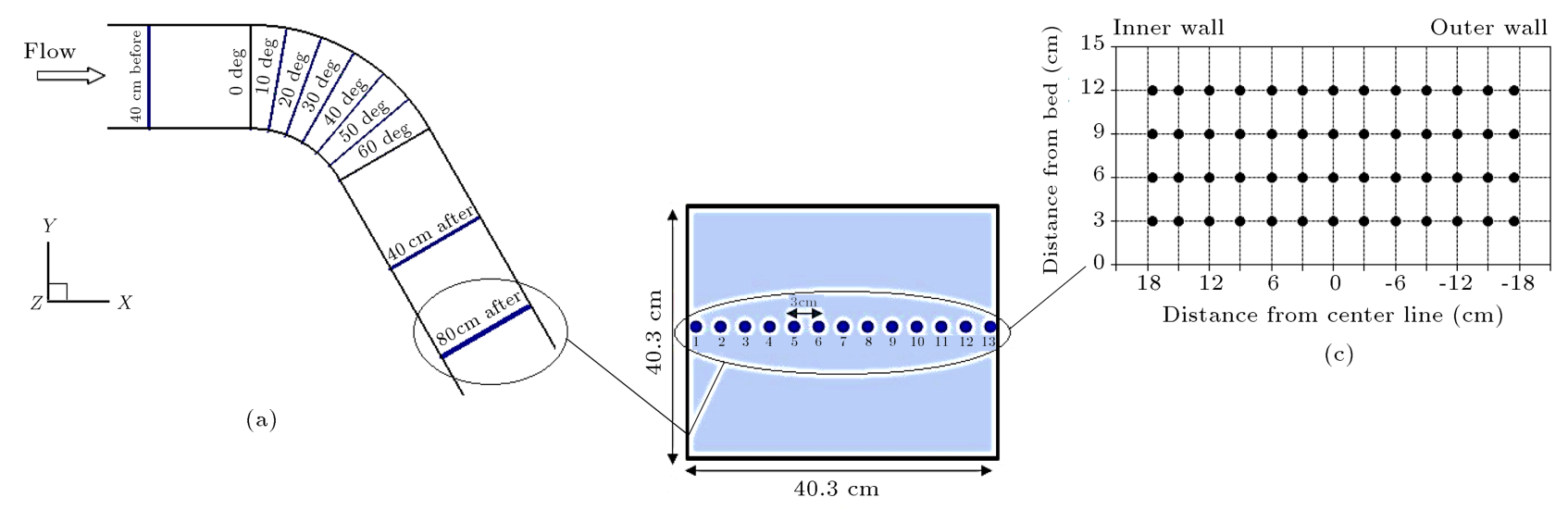

(b)

Figure 5. (a) 10 different cross sections, (b) 13 transverse points, and (c) the point coordinates in 4 distances from the channel bed to measure the velocity and water depth in $60^{\circ}$ bend.

more homogeneous the changes of the two variables, the higher the values of the correlation coefficients will be. The absolute value of the correlation coefficient, that is, the correlation coefficient without the sign $(+$ or ), indicates the strength of the correlation of the two variables. Generally, the closer the value obtained by the model to 1 , the closer it will be to the actual value and the better the performance of the model will be. Another index, namely, Bias, is applied to determine the performance of the model in estimating the values in comparison with observational data (overestimation or underestimation). The negative and positive values of Bias index represent the underestimation and overestimation of model performance, respectively. The mentioned indices are calculated in accordance with the following equations:

$$
\begin{aligned}
& R M S E=\left(\frac{1}{N} \sum_{i=1}^{N}\left(X_{o b s i}-X_{e s t i}\right)^{2}\right)^{\frac{1}{2}}, \\
& M A E=\frac{1}{N} \sum_{i=1}^{N}\left|X_{o b s i}-X_{e s t i}\right| \\
& M A P E(\%)=\frac{100}{N} \sum_{i=1}^{N}\left(\frac{\left|X_{o b s i}-X_{\text {est } i}\right|}{X_{\text {obsi }}}\right) \text {, } \\
& M A R E=\frac{1}{N} \sum_{i=1}^{N}\left(\frac{\left|X_{o b s i}-X_{e s t i}\right|}{X_{o b s i}}\right), \\
& R=\frac{\sum_{i=1}^{N}\left(X_{o b s_{i}}-\overline{X_{o b s_{i}}}\right) \cdot\left(X_{e^{s t_{i}}}-\overline{X_{e s t_{i}}}\right)}{\sqrt{\sum_{i=1}^{N}\left(X_{\exp i}-\overline{X_{\exp _{i}}}\right)^{2} \cdot \sum_{i=1}^{N}\left(X_{\text {esti }}-\overline{X_{e s t_{i}}}\right)^{2}}} \\
& \text { Bias }=\frac{1}{N} \sum_{i=1}^{N}\left(X_{e s t i}-X_{o b s i}\right)
\end{aligned}
$$

$X_{\text {obsi }}$ is the observed parameter in the abovementioned equations, $X_{\text {esti }}$ is the parameter estimated by the models, $\overline{X_{o b s}}$ is the mean observed parameter, $\overline{X_{\text {est }}}$ is the mean parameter estimated by the model, and $N$ is the number of the parameters.

\section{Results and discussions}

\subsection{Performance evaluation of velocity prediction models}

Figure 6 shows the scatter plot graphs for the velocity values predicted by FLUENT, SVM, and ANN models in comparison with the experimental values. It can be seen that the results of all the three models have an acceptable level of consistency with the observational values. All the data are within $\pm 20 \%$ range of the error line for all the three models. However, studying this figure carefully will make it clear that most of the data are around the exact line in the ANN model and they are not widely scattered. The data are more scattered in FLUENT and SVM models. Almost all of them are between the exact line and $-20 \%$ error line in the FLUENT model and between the $+20 \%$ and $-20 \%$ error lines in the SVM model. Most of them are concentrated around the exact line in the FLUENT model and the SVM results are located farther from the exact line. Therefore, the SVM model is less precise than the other models.

All the different statistical indices for predicting the velocity parameters and comparing the FLUENT, ANN, and SVM models are shown in Table 2. Note that all these indices are related to the whole datasets (train + test dataset) for SVM and ANN models. Regarding the velocity-predicting models, it is clear that the MARE relative error index of the ANN model, which is equal to 0.055 , is smaller than those of the rest of the models. It is followed by SVM with a relative error of 0.069 and then comes the FLUENT model with a relative error of 0.089 . The $M A R E$ index, 


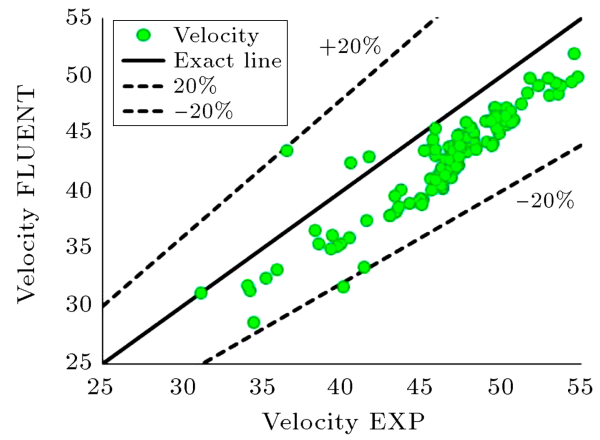

(a)

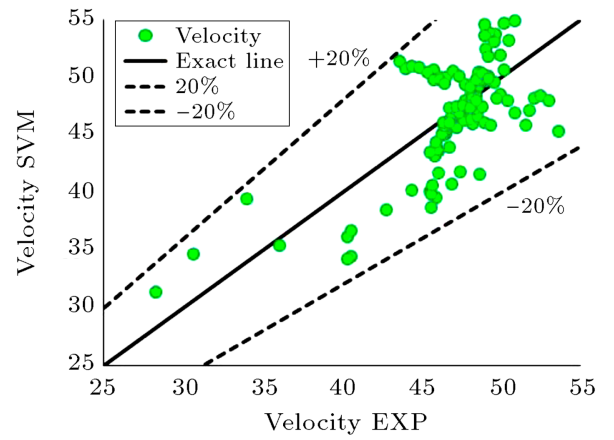

(b)

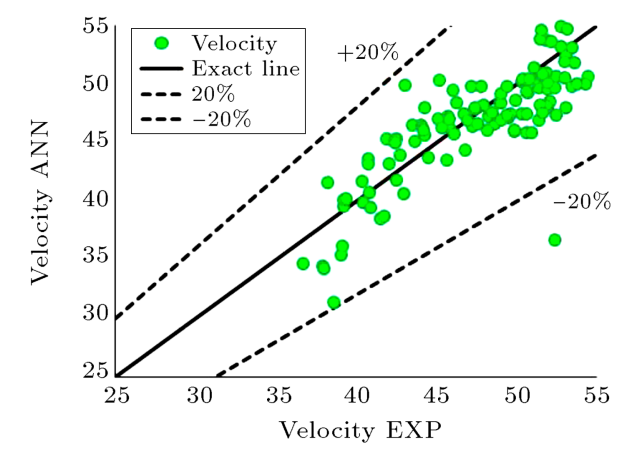

(c)

Figure 6. The scatter plot graphs for the velocity values predicted by (a) FLUENT, (b) SVM, and (c) ANN models in comparison with the experimental values.

Table 2. Assessing the performance of FLUENT, SVM, and ANN models in predicting the velocity in comparison with the experimental values through using different statistical indices.

\begin{tabular}{ccccccc}
\hline Variable & Models & $\boldsymbol{R} \boldsymbol{M S E}(\mathbf{c m})$ & $\boldsymbol{M A E} \mathbf{( c m )}$ & $\boldsymbol{M A R E}(\mathbf{c m})$ & $\boldsymbol{R}$ & Bias $(\mathbf{c m})$ \\
\hline \multirow{3}{*}{ Velocity prediction } & FLUENT & 4.500 & 4.251 & 0.089 & 0.95 & -4.124 \\
& SVM & 4.411 & 3.354 & 0.069 & 0.68 & -0.575 \\
& ANN & 3.497 & 2.642 & 0.055 & 0.81 & 0.098 \\
\hline
\end{tabular}

which is chosen as the appropriate evaluation scale for the comparison of models, represents the relative differences between the predicted and observed values. According to MARE values, the ANN model has the highest accuracy among other models and is the best model in the present paper. For making more clear comparison between presented models, other indices are considered. The $M A E$ index represents the absolute difference values between predicted and observed values. The absolute error values for this index also follow the same trend in all three models. The $M A E$ error values are equal to 2.642, 3.354, and 4.251 in ANN, SVM, and FLUENT models, respectively. Based on the values, the $M A E$ has the same scale and unit; therefore, the difference between predicted and observed values in ANN model has the smallest value among the models $(2.642 \mathrm{~cm})$. Thus, it can be said that, similar to $M A R E$ value, the $M A E$ value in ANN model has the smallest amount among the models, which indicates the slight difference between predicted and observed values (almost $2 \mathrm{~cm}$ ) and high efficiency of ANN model. In addition to the difference between predicted and observed values, the performance of the models in estimating either higher and lower values than observed values is significant in evaluation. In this respect, the Bias index shows the overestimation and underestimation of the models with negative values indicating underestimation and the positive ones indicating overestimation. According to the Bias values, both the FLUENT and SVM models predict lower and the ANN model forecasts higher values than that of the experimental model. Therefore, it can be concluded that the ANN model is overestimating and FLUENT and SVM models are underestimating. Another error index is $R M S E$, which is suitable for the performance of models with higher data values. The difference between predicted and observed values in this scale is squared and higher $R M S E$ values represent higher error and consequently, higher difference in the data. In velocity prediction models, the ANN model with the 
smallest $R M S E$ value (almost $3.5 \mathrm{~cm}$ ) performs more efficiently than other models. The FLUENT model with the highest $R M S E$ value $(4.5 \mathrm{~cm})$ represents the weakest performance among all models, especially with high data values. The $R$ value presents the correlation between the data of the model and the experimental values, and the correlation of two variables as well as the direction of the correlation. This value is greatest in the FLUENT model among all of them $(R=0.952)$. However, it can be seen from Figure 6 (a) that the predicted data by FLUENT model are scattered between the exact line and the $-20 \%$ error line. In this model, the trend line is parallel to the exact line, and despite the fact that the $R$ value in this model is close to one, it cannot be said that this model is the most accurate model in prediction of the flow velocity. Considering the large error values in Table 2, this model performs the worst in comparison with ANN and SVM models in the prediction of flow velocity. This model predicts all velocity values less than experimental ones with error values of $10-20 \%$. Almost the whole data are predicted by the FLUENT model in this error range. In addition, the high amounts of Bias value (also negative signs) approve the underestimating performance of the FLUENT model. This can be considered as a disadvantage for the FLUENT model that it estimates lower than a certain error value in prediction of the flow pattern. Despite smaller values of $R$ in ANN and SVM models than in FLUENT model, the lower values of error indices and more logical data distribution in scatter graphs between error lines and exact line in these models than in the FLUENT model represent the high efficiency of these models. However, as it was mentioned previously, the ANN model with the lowest error values is the best model in the velocity prediction in this study.

\subsection{Performance evaluation of water surface depth prediction models}

The scatter plot graphs of the water depths predicted by these models are shown in Figure 7 . The water surface depth values predicted by all the three models have an acceptable agreement with the observed data. The data are concentrated around the exact line in all the three models. However, careful examination of the images will clarify that all the data are within the $\pm 5 \%$ error line range in the ANN model. After that, in the FLUENT model, a few data fall outside the $+5 \%$ error line and then, in the SVM model, more data exceed this error line.

The error indices are gathered in Table 3 for making better comparison between all models for the whole datasets. It could be seen in the flow depth predicting models that the difference between the predicted values and the experimental values is smaller for the ANN model than for the other models $(M A E=0.052 \mathrm{~cm})$. The SVM and FLUENT models have smaller absolute error values, respectively, after the ANN model $(0.105 \mathrm{~cm}$ and $0.169 \mathrm{~cm}$ for FLUENT and SVM models, respectively). Also, as in the velocity prediction, the

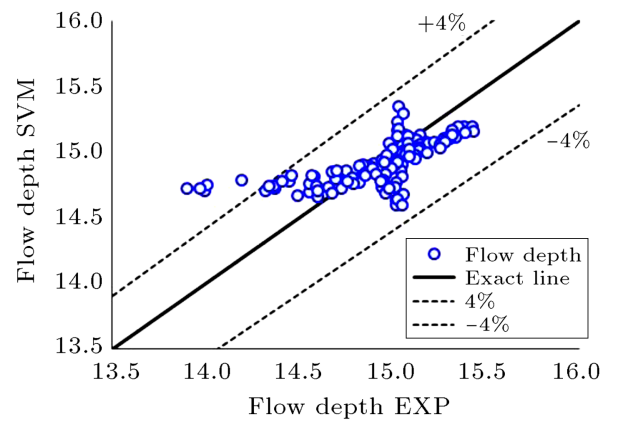

(b)

(a)

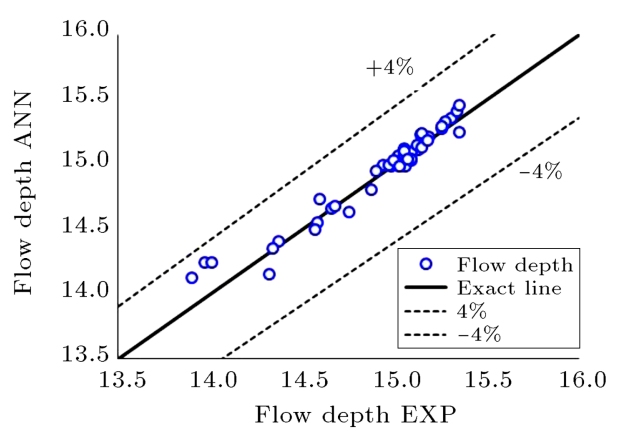

(c)

Figure 7. The scatter plot graphs for the water depth values predicted by (a) FLUENT, (b) SVM, and (c) ANN models in comparison with the experimental values. 
Table 3. Assessing the performance of FLUENT, SVM, and ANN models in predicting the flow depth in comparison with the experimental values.

\begin{tabular}{ccccccc}
\hline Variable & Models & $\boldsymbol{R} \boldsymbol{M S E}(\mathbf{c m})$ & $\boldsymbol{M A E}(\mathbf{c m})$ & $\boldsymbol{M A R} \boldsymbol{E}(\mathbf{c m})$ & $\boldsymbol{R}$ & $\boldsymbol{B i a s}(\mathbf{c m})$ \\
\hline \multirow{3}{*}{ Flow depth prediction } & FLUENT & 0.135 & 0.105 & 0.007 & 0.914 & -0.012 \\
& SVM & 0.228 & 0.169 & 0.011 & 0.696 & -0.028 \\
& ANN & 0.074 & 0.052 & 0.004 & 0.999 & 0.006 \\
\hline
\end{tabular}

relative error is smaller in the ANN model than in the other models when predicting the water depth $(M A R E=0.004)$. The relative error index in ANN model is improved almost $43 \%$ and $64 \%$ in comparison with the FLUENT and SVM models, respectively. In comparison with the velocity prediction models, the ANN model has the smallest absolute $R M S E$ value $(R M S E=0.074)$. Therefore, this model also has an acceptable efficiency in prediction of high flow depth values. On the other hand, the correlation coefficient (which is described as the relationship between the predicted and observed values) in ANN model has high values (almost close to 1 ) that confirm the high accuracy of ANN model. Thus, it can be concluded that the ANN model with the lowest error index is the best model in flow depth prediction among all the models. The FLUENT and SVM models predict the water surface with underestimation and the ANN model predicts the water surface with overestimation. The Bias value in ANN model is close to 1, which approves the high accuracy of this model in flow depth prediction. The $R$ values of FLUENT and SVM models are smaller (0.914 and 0.696) than that of the ANN model (0.999). In SVM model, the $R$ index value is described as the weakness of the model in water depth prediction.

\subsection{Transverse depth-averaged velocity profiles}

Figure 8 shows the transverse profiles of the depth averaged velocity in $25.3 \mathrm{l} / \mathrm{s}$ discharge in different transverse cross sections by all the three models. It could be seen in these graphs that all the three models, i.e. ANN, SVM, and FLUENT, perform well in predicting the velocity. All the three models are very well able to simulate the longitudinal velocity values in various cross sections in such a manner that the maximum velocity is placed, and maintained, in the inner wall of the channel up to the final cross sections of the bend. At the $60^{\circ}$ cross section, the maximum velocity gradually separates from the inner wall of the channel and transfers to the channel axis; then, it is totally placed outside the channel in the cross sections located after the bend. It could be seen in these figures that all the three models perform well in predicting the velocity pattern, but they are somehow different when it comes to predicting the velocity values. Table 4 shows the RMSE and MAPE error values for these cross sections in all three models. It could be seen in the table that with smaller error values, the ANN model performs averagely better than the other two models $(R M S E=3.31$ and $M A P E=5.57 \%$ ). In the following are the SVM model and the FLUENT model in predicting the velocity with $M A P E$ values of $7.14 \%$ and $8.69 \%$, respectively. The relative error index in ANN model, almost 5\%, represents the high accuracy of the model in velocity prediction, especially $80 \mathrm{~cm}$ after the bend cross section (MAPE value of almost $5 \%$ and $R M S E$ of almost $3 \mathrm{~cm}$ ) unlike SVM and FLUENT models with high error values in this cross section. The high value of relative error in SVM model in

Table 4. Calculating the RMSE and MAPE errors for depth averaged velocity by FLUENT, ANN, and SVM models in comparison with the experimental values in $25.3 \mathrm{l} / \mathrm{s}$ discharge in different cross sections.

\begin{tabular}{|c|c|c|c|c|c|c|}
\hline \multirow[b]{2}{*}{ Cross section } & \multicolumn{2}{|c|}{ FLUENT } & \multicolumn{2}{|c|}{ ANN } & \multicolumn{2}{|c|}{ SVM } \\
\hline & $R M S E(\mathrm{~cm})$ & $M A P E(\%)$ & $R M S E(\mathrm{~cm})$ & $M A P E(\%)$ & $R M S E(\mathrm{~cm})$ & $M A P E(\%)$ \\
\hline $40 \mathrm{~cm}$ before & 3.96 & 7.88 & 3.23 & 5.95 & 4.14 & 6.59 \\
\hline $0^{\circ}$ & 3.97 & 7.82 & 2.68 & 4.57 & 2.90 & 5.45 \\
\hline $10^{\circ}$ & 5.04 & 9.95 & 3.48 & 5.96 & 4.50 & 6.51 \\
\hline $20^{\circ}$ & 4.81 & 9.74 & 3.64 & 5.74 & 5.44 & 8.48 \\
\hline $30^{\circ}$ & 5.12 & 10.14 & 4.20 & 6.30 & 5.80 & 8.89 \\
\hline $40^{\circ}$ & 4.97 & 10.06 & 3.24 & 4.71 & 5.34 & 8.24 \\
\hline $50^{\circ}$ & 4.03 & 8.29 & 2.28 & 4.19 & 3.89 & 6.20 \\
\hline $60^{\circ}$ & 4.13 & 8.52 & 5.40 & 7.61 & 1.88 & 3.13 \\
\hline $40 \mathrm{~cm}$ after & 4.04 & 8.07 & 3.92 & 7.09 & 3.23 & 6.62 \\
\hline $80 \mathrm{~cm}$ after & 4.69 & 9.12 & 1.62 & 2.94 & 5.33 & 11.29 \\
\hline Averaged & 4.48 & 8.96 & 3.37 & 5.51 & 4.245 & 7.14 \\
\hline
\end{tabular}



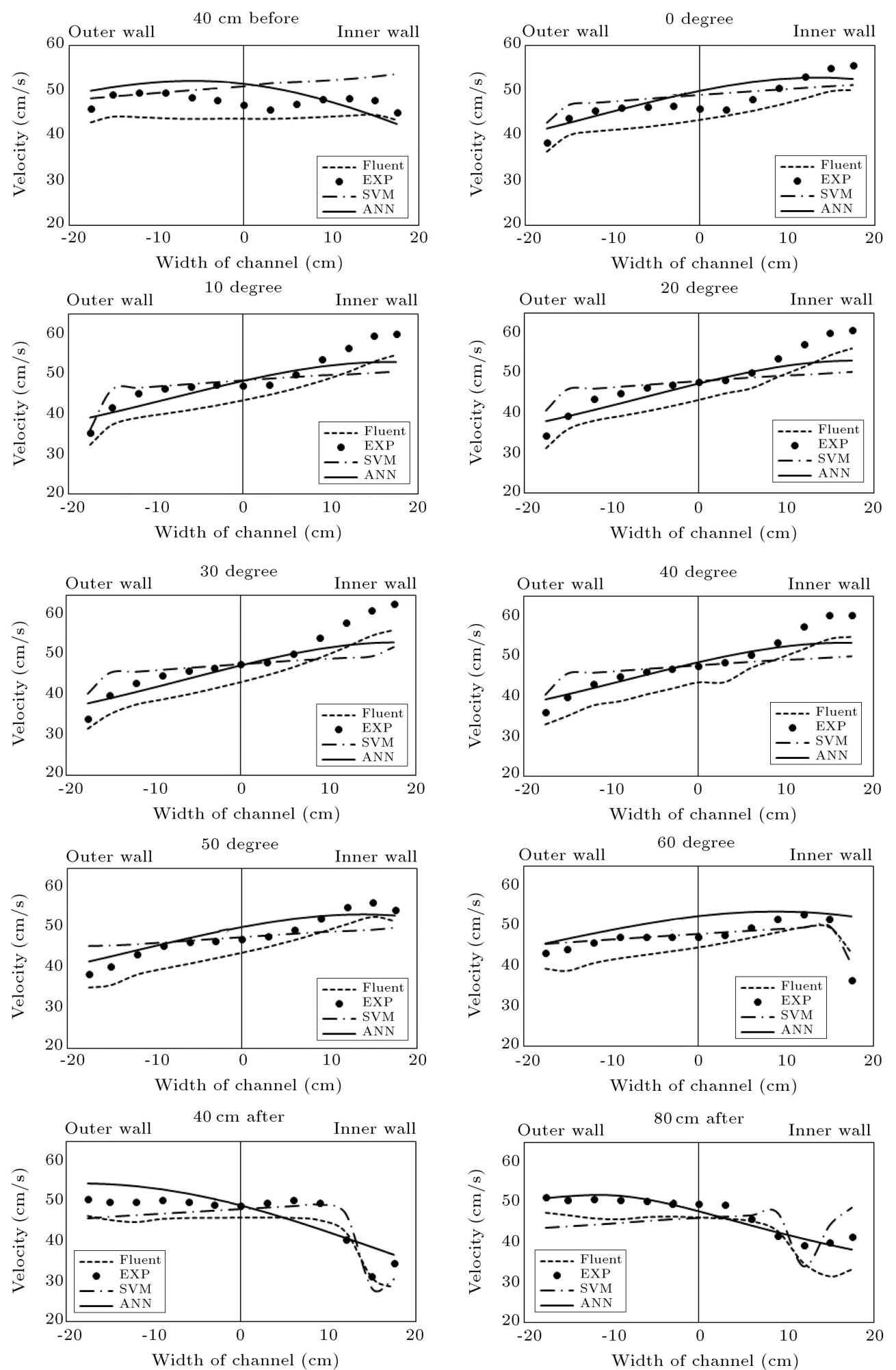

Figure 8. The transverse depth averaged velocity distribution in different cross sections with $25.3 \mathrm{l} / \mathrm{s}$ discharge by three ANN, SVM, and FLUENT models.

$80 \mathrm{~cm}$ after the bend cross section $(M A P E=11.29 \%)$ demonstrates the low accuracy of this model in velocity prediction. The ANN model has smaller relative error in $40^{\circ}$ and $50^{\circ}$ cross sections than other models (almost $4 \%$ ), which represents the high performance of the model in these cross sections. However, the $R M S E$ error is generally lower in ANN model for all cross sections, which shows the high proficiency of it in predicting high values of velocity. Finally, it can be concluded that the ANN model has smaller error values 
and performs better than the other two models in all the cross sections and it is the best model in velocity prediction at transverse cross sections. However, The SVM model is more precise for the $60^{\circ}$ cross section and for the cross section located $40 \mathrm{~cm}$ after the bend, especially in prediction of high velocity values, which leads to a lower $R M S E$ value $(1.88 \mathrm{~cm})$.

\subsection{Transverse water surface profiles}

Table 5 shows RMSE and MAPE error values for the transverse profiles of the water surface in different cross sections by all the three FLUENT, ANN, and SVM models with $25.3 \mathrm{l} / \mathrm{s}$ discharge in comparison with the experimental values. All the three models have moderate $R M S E$ and $M A P E$ values and thus, perform better than the velocity prediction models. According to Table 5, with smaller error values $(R M S E=0.380$ and $M A P E=0.07 \%$ ), the ANN model performs better than the other two models as well as the velocity models. FLUENT and SVM models perform at an acceptable level after ANN ( $M A P E=0.128 \%$ and $0.212 \%$, respectively). The lower $R M S E$ value in ANN model (almost under $0.1 \mathrm{~cm}$ ) illustrates the high accuracy of this model in predicting of all amounts of flow depth, especially before the cross sections and in the internal cross sections of the bend $\left(20^{\circ}\right.$ and $30^{\circ}$ cross sections). The SVM and FLUENT models have high relative errors, almost $67 \%$ and $45 \%$ higher than that of the ANN model, respectively, which show their lower accuracy. The FLUENT model with more $R M S E$ values (almost higher than $0.1 \mathrm{~cm}$ ) has lower efficiency in predicting of high values of flow depth than the other model. In general, the ANN model with a very small relative error index $(0.07 \%)$ and lower $R M S E$ value (high performance in estimating flow depths with high amounts) is the best model in this section.

Figure 9 shows the error contours in the bend plan as $e=\left(h_{\exp }-h_{\text {model }} / h_{\exp }\right)$ in percentage for predicting the water depth by the all three models in comparison with the experimental results. The error range is smaller in the ANN model than in the other two models in the entire bend (-1.2 to 1.6$)$. The error value is lower in the inner wall in the ANN model than in the SVM and FLUENT models in such a manner that the ANN model is the best model in the cross sections within the bend, enjoying an error value of approximately zero. The FLUENT model comes after with an error value of almost $1 \%$ and then comes the SVM model with an approximate error value of $3-4 \%$. The error value is smaller in the outer wall (contraction zone) than in the inner wall (separation zone) in all the three models (it is almost half that in the inner wall in the FLUENT model, almost one third in the SVM model, and 0.4 in the ANN model). Therefore, it could be stated that the error values in the zones with maximum velocities are higher than those in the zones with minimum velocities. Also, in three ANN, SVM and FLUENT models, the lower error values in the sections after the bend can be negligible. The error value is insignificant in the cross sections after the bend in all the three models in such a manner that it is between -0.4 and 0.4 in the ANN model and it is almost zero in the cross sections near the exit. In all models, the error values in initial bend cross sections are almost equal to zero. The error contours are more concentrated in the inner wall than in the outer wall of the channel in all three models, which is due to the density of the streamlines in this wall.

\section{Conclusion}

In this study, two numerical techniques, namely computational fluid dynamics and soft computing, were investigated in the prediction of the three-dimensional flow pattern on curves. Also, due to the complexity of the flow pattern in sharp curves, a $60^{\circ}$ sharp bend

Table 5. Calculating the RMSE and MAPE errors for water surface depth prediction by the models in comparison with the experimental values in $25.3 \mathrm{l} / \mathrm{s}$ discharge in different cross sections.

\begin{tabular}{|c|c|c|c|c|c|c|}
\hline \multirow[b]{2}{*}{ Cross section } & \multicolumn{2}{|c|}{ FLUENT } & \multicolumn{2}{|c|}{ ANN } & \multicolumn{2}{|c|}{ SVM } \\
\hline & $R M S E(\mathrm{~cm})$ & MAPE (\%) & $R M S E(\mathrm{~cm})$ & $M A P E(\%)$ & $R M S E(\mathrm{~cm})$ & $M A P E(\%)$ \\
\hline $40 \mathrm{~cm}$ before & 0.035 & 0.21 & 0.031 & 0.153 & 0.250 & 1.395 \\
\hline $0^{\circ}$ & 0.085 & 0.50 & 0.084 & 0.428 & 0.062 & 0.373 \\
\hline $10^{\circ}$ & 0.154 & 0.750 & 0.064 & 0.377 & 0.243 & 1.157 \\
\hline $20^{\circ}$ & 0.099 & 0.540 & 0.041 & 0.210 & 0.214 & 1.225 \\
\hline $30^{\circ}$ & 0.209 & 0.968 & 0.048 & 0.335 & 0.368 & 1.792 \\
\hline $40^{\circ}$ & 0.150 & 0.809 & 0.100 & 0.564 & 0.308 & 1.707 \\
\hline $50^{\circ}$ & 0.134 & 0.735 & 0.089 & 0.385 & 0.139 & 0.724 \\
\hline $60^{\circ}$ & 0.121 & 0.691 & 0.093 & 0.428 & 0.161 & 0.986 \\
\hline $40 \mathrm{~cm}$ after & 0.153 & 1.001 & 0.080 & 0.413 & 0.221 & 1.221 \\
\hline $80 \mathrm{~cm}$ after & 0.137 & 0.886 & 0.070 & 0.380 & 0.157 & 0.830 \\
\hline Averaged & 0.709 & 0.128 & 0.380 & 0.07 & 1.141 & 0.212 \\
\hline
\end{tabular}




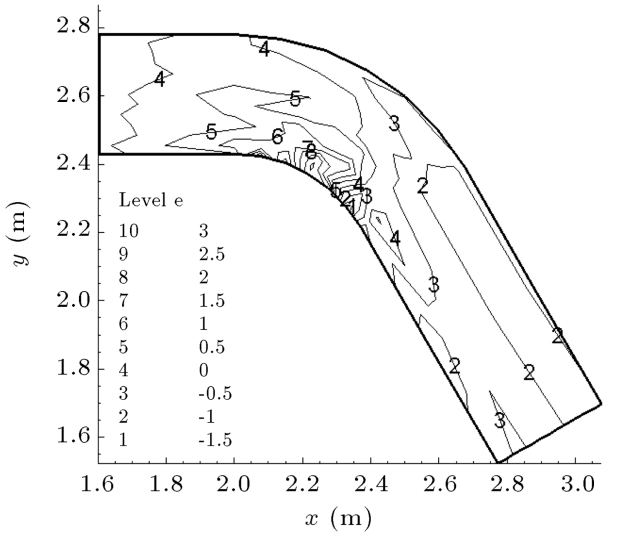

(a)

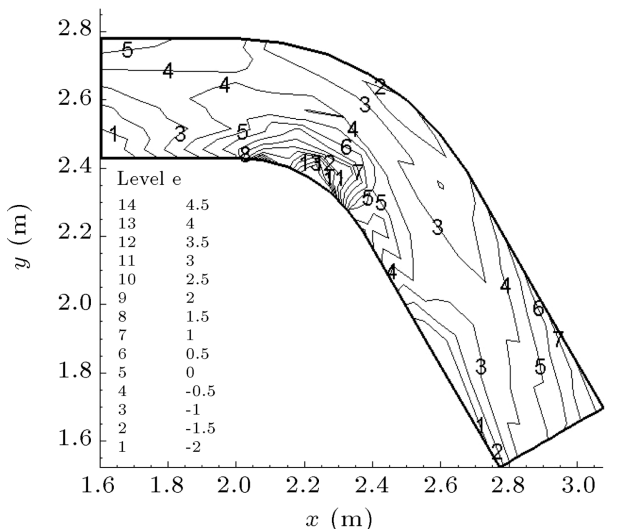

(b)

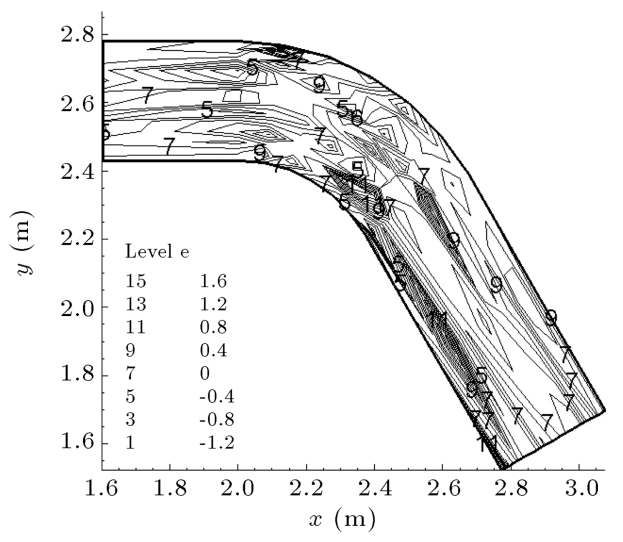

(c)

Figure 9. Water surface prediction error contours in the bend plan with $e=\left(h_{\exp }-h_{\text {model }} / h_{\exp }\right)$ in percentage by all the three models: (a) FLUENT, (b) SVM, and (c) ANN.

was chosen and extensive experimental research by the authors was performed on it. The advantage of this study is that experimental studies were done in 6 different hydraulic conditions and the experimental results were used for training and testing the artificial intelligence models. The results showed that, compared to experimental values, all the three ANN, SVM, and CFD models performed well with acceptable errors in prediction of two velocity and water depth variables. ANN model predicted both the velocity and water surface variables with lower error value and was the superior model. FLUENT model estimated velocity values with errors about $10-20 \%$ and showed the lowest accuracy. In despite of this, it gave us the certainty that this model in velocity prediction in the curved channels had a certain achievement. However, FLUENT model, following the ANN model, was the best, because using turbulence model nonlinear, $k-\varepsilon$ (RNG), led to more accurate prediction of the water free surface. In general, ANN and SVM methods, with lower time and cost than the expensive experimental methods and CFD model, are more appropriate. However, the CFD model, because of complex Navier-Stokes equations governing the flow curves, and experimental methods, due to the governing physics in the flow, are important as well. Other data division methods have been proposed to decrease and increase the error values and model accuracy, respectively.

\section{References}

1. Baghlani, A. "Simulation of flow and mass dispersion in meandering channels", Scientia Iranica, Transactions A: Civil Engineering, 19, pp. 1463-1472 (2012).

2. Shukry, A. "Flow around bends in an open flume", Transactions, ASCE, 115, pp. 751-788 (1950).

3. Rozovskii, I.L. "Flow of water in bends of open channels", Israel Program for Science Translation, Jerusalem, pp. 1-233 (1961).

4. DeVriend, H.J. and Geoldof, H.J. "Main flow velocity in short river bends", Journal of Hydraulics Engineering, 109(7), pp. 991-1011 (1983).

5. Bergs, M.A. "Flow processes in a curved alluvial channel", Ph.D. Thesis, The University of Iowa (1990).

6. Ye, J. and McCorquodale, J.A. "Simulation of curved open channel flows by 3D hydrodynamic model", Journal of Hydraulic Engineering- ASCE, 124(7), pp. 687-698 (1998). 
7. Blanckaert, K. and Graf, W.H. "Mean flow and turbulence in open channel bend", Journal of Hydraulic Engineering, 127(10), pp. 835-847 (2001).

8. Barbhuiya, A.K. and Talukdar, S. "Scour and three dimensional turbulent flow fields measured by ADV at a $90^{\circ}$ horizontal forced bend in a rectangular channel", Flow Measurement and Instrumentation, 21, pp. 312321 (2010).

9. Ramamurthy, A., Han, S., and Biron, P. "Threedimensional simulation parameters for $90^{\circ}$ open channel bend flows", Journal of Computing in Civil Engineering. ASCA, 27(3), pp. 282-291 (2013).

10. Gholami, A., Akhtari, A.A., Minatour, Y., Bonakdari, H., and Javadi, A.A. "Experimental and numerical study on velocity fields and water surface profile in a strongly-curved $90^{\circ}$ open channel bend", Engineering Applications of Computational Fluid Mechanics, 8(3), pp. 447-461 (2014).

11. Leschziner, M.A. and Rodi, W. "Calculation of strongly curved open channel flow", Journal of the Hydraulics Division, 105(10), pp. 1297-1314 (1979).

12. Naji, M.A., Ghodsian, M., Vaghefi, M., and Panahpur, $\mathrm{N}$. "Experimental and numerical simulation of flow in a $90^{\circ}$ bend", Flow Measurement and Instrumentation, 21(3), pp. 292-298 (2010).

13. DeMarchis, M. and Napoli, E. "3D numerical simulation of curved open channel flows", Proceedings of 6th International Conference on Water Resources, Hydraulics \& Hydrology, pp. 86-91, Chalkida, Evia Island, Greece, May 11-13 (2006).

14. Bodnar, T., Prihoda, J. "Numerical simulation of turbulent free-surface flow in curved channel", Flow, Turbulence and Combustion, 76, pp. 429-442 (2006).

15. Gholami, A., Bonakdari, H., and Akhtari, A.A. "Assessment of water depth change patterns in 120 sharp bend using numerical model", Water Science and Engineering, 4(9), pp. 336-344 (2016).

16. Bonakdari, H., Larrarte, F., and Joannis, C. "Effect of a bend on the velocity field in a circular sewer with free surface flow", Proceeding of 6th International Conference on Sustainable Techniques and Strategies in Urban Water Management, pp. 1401-1408, Lyon, France, June 24-28 (2007).

17. Zeng, J., Constantinescu, G., Blanckaert, K., and Weber, L. "Flow and bathymetry in sharp openchannel bends: Experiments and predictions", Water Resources Research, 44(9), w09401, pp. 1-22 (2008).

18. Gholami, A., Bonakdari, H., and Akhtari, A.A. "Developing finite volume method (FVM) in numerical simulation of flow pattern in $60^{\circ}$ open channel bend", Journal of Applied Research in Water and Wastewater, 3(1), pp. 193-200 (2016).

19. Kisi, O. and Cigizoglu, H.K. "Comparison of different ANN techniques in river flow prediction", Civil Engineering Environment System, 14, pp. 211-231 (2007).
20. Najafzadeh, M. and Azamathulla, H.M. "Neuro-fuzzy GMDH to predict the scour pile groups due to waves", Journal of Computing in Civil Engineering, 29(5), 04014068 (2013).

21. Najafzadeh, M., Barani, G.A., and Hessami Kermani, M.R. "Estimation of pipeline scour due to waves by GMDH", Journal of Pipeline Systems Engineering and Practice, 5(3), 06014002 (2014).

22. Najafzadeh, M. and Zahiri, A. "Neuro-fuzzy GMDHbased evolutionary algorithms to predict flow discharge in straight compound channels", Journal of Hydrologic Engineering, 20(12), 04015035 (2015).

23. Najafzadeh, M., Barani, G.A., and Hessami-Kermani, M.R. "Evaluation of GMDH networks for prediction of local scour depth at bridge abutments in coarse sediments with thinly armored beds", Ocean Engineering, 104, pp. 387-396 (2015).

24. Najafzadeh, M., Etemad-Shahidi, A., and Lim, S.Y. "Scour prediction in long contractions using ANFIS and SVM", Ocean Engineering, 111, pp. 128-135 (2016).

25. Najafzadeh, M., Balf, M.R., and Rashedi, E. "Prediction of maximum scour depth around piers with debris accumulation using EPR, MT, and GEP models", Journal of Hydroinformatics, 18(5), pp. 867-884 (2016).

26. Najafzadeh, M. and Sattar, A.M. "Neuro-fuzzy GMDH approach to predict longitudinal dispersion in water networks", Water Resources Management, 29(7), pp. 2205-2219 (2015).

27. Gholami, A., Bonakdari, H., Ebtehaj, I., and Akhtari, A.A. "Design of an adaptive neuro-fuzzy computing technique for predicting flow variables in a $90^{\circ}$ sharp bend", Journal of Hydroinformatics, 19(4), jh2017200 (2017).

28. Gholami, A., Bonakdari, H., Zaji, A.H., Fenjan, S.A., and Akhtari, A.A. "New radial basis function network method based on decision trees to predict flow variables in a curved channel", Neural Computing and Applications, 30(9), pp. 2771-2785 (2018).

29. Gholami, A., Bonakdari, H., Zaji, A.H., Ajeel Fenjan, S., and Akhtari, A.A. "Design of modified structure multi-layer perceptron networks based on decision trees for the prediction of flow parameters in 90 openchannel bends", Engineering Applications of Computational Fluid Mechanics, 10(1), pp. 193-208 (2016).

30. Gholami, A., Bonakdari, H., Ebtehaj, I., Shaghaghi, S., and Khoshbin, F. "Developing an expert group method of data handling system for predicting the geometry of a stable channel with a gravel bed", Earth Surface Processes and Landforms, 42(10), pp. 14601471 (2017). DOI: $10.1002 /$ esp.4104 
31. Shaghaghi, S., Bonakdari, H., Gholami, A., Ebtehaj, I., and Zeinolabedini, M. "Comparative analysis of GMDH neural network based on genetic algorithm and particle swarm optimization in stable channel design", Applied Mathematics and Computation, 313, pp. 271286 (2017).

32. Kaveh, A. and Nasrollahi, A. "Charged system search and particle swarm optimization hybridized for optimal design of engineering structures", Scientia Iranica, Transactions A: Civil Engineering, 21, pp. 295-305 (2014).

33. Ebtehaj, I., Bonakdari, H., Zaji, A.H., Azimi H., and Sharifi, A. "Gene expression programming to predict the discharge coefficient in rectangular side weirs", Applied Soft Computing, 35, pp. 618-628 (2015).

34. Karimi, S., Bonakdari, H., and Gholami, A. "Determination discharge capacity of triangular labyrinth side weir using multi-layer neural network (ANN-MLP)", Current World Environment, 10(Special issue 1), pp. 111-119 (2015).

35. Zarif Sanayei, H.R., Talebbeydokhti, N., and Moradkhani, H. "3D estimation of metal elements in sediments of the Caspian Sea with moving least square and radial basis function interpolation methods", Scientia Iranica, Transactions A: Civil Engineering, 22, pp. 1661-1673 (2015).

36. Bonakdari, H., Baghalian, S., Nazari, F., and Fazli, M. "Numerical analysis and prediction of the velocity field in curved open channel using artificial neural network and genetic algorithm", Engineering Applications of Computational Fluid Mechanics, 5(3), pp. 384-396 (2011).

37. Sahu, M., Jana, S., Agarwal, S., and Khatua, K.K. "Point form velocity prediction in meandering open channel using artificial neural network", 2nd International Conference on Environmental Science and Technology, 6, pp. 209-212, Singapore: IACSIT Press (2011).

38. Gholami, A., Bonakdari, H., Zaji, A.H., and Akhtari, A.A. "Simulation of open channel bend characteristics using computational fluid dynamics and artificial neural networks", Engineering Applications of Computational Fluid Mechanics, 9(1), pp. 355-361 (2015).

39. Fenjan, S.A., Bonakdari, H., Gholami, A., and Akhtari, A.A. "Flow variables prediction using experimental, computational fluid dynamic and artificial neural network models in a sharp bend", International Journal of Engineering-Transactions A: Basics, 29(1), pp. 14-21 (2016).

40. Gholami, A., Bonakdari, H., Zaji, A.H., Akhtari, A.A., and Khodashenas, S.R. "Predicting the velocity field in a $90^{\circ}$ open channel bend using a gene expression programming model", Flow Measurement and Instrumentation, 46, pp. 189-192 (2015).
41. Gholami, A., Bonakdari, H., Zaji, A.H., Michelson, D.G., and Akhtari, A.A. "Improving the performance of multi-layer perceptron and radial basis function models with a decision tree model to predict flow variables in a sharp $90^{\circ}$ bend", Applied Soft Computing, 48, pp. 563-583 (2016).

42. Akhtari, A.A., Abrishami, J., and Sharifi, M.B. "Experimental investigations water surface characteristics in strongly-curved open channels", Journal of Applied Sciences, 9(20), pp. 3699-3706 (2009).

43. Armfield Limited, Co., Instruction Manual of Miniature Propeller Velocity Meter Type H33 (1995).

44. Fluent Manual, Manual and User Guide of Fluent Software, Fluent Inc (2005).

45. Rezaeian Zadeh, M., Amin, S., Khalili, D., and Singh, V.P. "Daily outflow prediction by multilayer perception with logistic sigmoid and tangent sigmoid activation functions", Journal of Water Resources Management, 24(11), pp. 2673-2688 (2010).

46. Ebtehaj, I. and Bonakdari, H. "Evaluation of sediment transport in sewer using artificial neural network", Engineering Applications of Computational Fluid Mechanics, 7(3), pp. 382-392 (2013).

47. Levenberg, K. "A method for the solution of certain non-linear problems in least-squares", The Quarterly of Applied Mathematics, 2, pp. 164-168 (1944).

48. Zaji, A.H. and Bonakdari, H. "Application of artificial neural network and genetic programming models for estimating the longitudinal velocity field in open channel junctions", Flow Measurement and Instrumentation, 41, pp. 81-89 (2015).

49. Vapnik, V., The Nature of Statistical Learning Theory, Springer Verlag, New York, USA (1995)

50. Vapnik, V.N. and Vapnik, V., Statistical Learning Theory, 1, Wiley, New York (1998).

51. Adarsh, S. "Prediction of longitudinal dispersion coefficient in natural channels using soft computing techniques", Scientia Iranica. Transaction A, Civil Engineering, 17(5), pp. 363-371 (2010).

52. Wang, R., Zhan, Y., and Zhou, H. "Application of transform in fault diagnosis of power electronics circuits", Scientia Iranica, 19(3), pp. 721-726 (2012).

53. Ebtehaj, I., Bonakdari, H., Shamshirband, S., and Mohammadi, K. "A combined support vector machinewavelet transform model for prediction of sediment transport in sewer", Flow Measurement and Instrumentation, 47, pp. 19-27 (2016).

54. Ebtehaj, I. and Bonakdari, H. "A support vector regression-firefly algorithm-based model for limiting velocity prediction in sewer pipes", Water Science \& Technology, 73(9), pp. 2244-2250 (2016). 
55. Bowden, G.J., Maier, H.R., and Dandy, G.C. "Optimal division of data for neural network models in water resources applications", Water Resources Research, 38(2), pp. 1-11 (2002).

\section{Biographies}

Azadeh Gholami is now $\mathrm{PhD}$ candidate in Hydraulic Structures in the Department of Civil Engineering at Razi University, Kermanshah, Iran. She works in the field of hydraulic of bends. She has more than 20 contributions to journals as well as national and international conferences.

Hossein Bonakdari is Professor in the Department of Civil Engineering at Razi University. He received his $\mathrm{PhD}$ in Civil Engineering from the University of Caen, France. After receiving $\mathrm{PhD}$, has joined Razi University as a faculty member in 2006 and presently, he is a Full Professor in the Department of Civil Engineering. He has supervised $5 \mathrm{PhD}$ and $30 \mathrm{MS}$ theses with teaching experience of more than 16 years in the field of civil en gineering. Furthermore, from 2013 to 2015, he was Director General of Training, Research and Technology Development at Ministry of Energy, Iran and Deputy of Planning \& Development in National Water and Wastewater Engineering Company, Iran, from 2011-2013. His fields of specialization and interest include practical application of soft computing in engineering, modeling of wastewater urban drainage systems, sediment transport, computational fluid dynamics and hydraulics, design of hydraulic structures, and fluid mechanics. From 2010 to 2011, he was researcher at Laboratory of Civil and Environmental Engineering, INSA of Lyon, France. Results obtained from his researches have been published in more than 130 papers in international journals (h-index $=15$ ). He also has more than 150 presentations in national and international conferences and has published two books. He has been rated as distinguished researcher at Razi University in 2014, 2015, and 2016.

Ali Akbar Akhatri is Assistant Professor in the Department of Civil Engineering at Razi University. He received his $\mathrm{PhD}$ degree from Ferdowsi University of Mashhad, Iran. Currently, he is president of Kermanshah University of Technology. He has supervised $3 \mathrm{PhD}$ and $30 \mathrm{MS}$ theses with teaching experience of more than 20 years in the field of Civil Engineering. He is working in hydraulics, hydraulic structures, and fluid mechanics. He has published more than 70 contributions in journals as well as national and international conferences.

Isa Ebtehaj is now $\mathrm{PhD}$ candidate in Hydraulic Structures (Civil Engineering) in the Department of Civil Engineering, Razi University, Kermanshah, Iran. He has 30 published papers in ISI journals. He works in the field of soft computing methods in engineering applications. 